\title{
PUBLIC INVESTMENT IN A HIERARCHICAL EDUCATIONAL SYSTEM WITH CAPITAL-SKILL COMPLEMENTARITY
}

\author{
AsSAF SARID \\ Tel Aviv University
}

In this study I bring together two different literatures: the hierarchical education literature and the skill-biased growth literature. In an overlapping-generations model I introduce capital-skill complementarity into a hierarchical education system. I obtain results that differ qualitatively from previous studies, among which are the following: (i) At earlier stages of development, basically educated labor contributes to growth more than highly educated labor. The opposite occurs at later stages. (ii) Even when all individuals acquire higher education, a growth-enhancing policy subsidizes higher education. (iii) In a growth-enhancing policy, the share of public resources allocated to basic education declines as the economy grows. (iv) The enrollment rate evolves in an S-shaped pattern, as occurred in several OECD countries.

Keywords: Education and Development, Government Educational Expenditures, Human Capital, Life-Cycle Models

\section{INTRODUCTION}

There is abundant empirical evidence that investment in education accelerates economic growth [Barro (1991)]. This finding is usually explained by using the human capital theory, which states that education adds to human capital and therefore increases productivity. A new strand in the literature-the hierarchical education literature- has recently modeled human capital accumulation as a twostage process: acquiring basic education in primary and secondary schools as a prerequisite for acquiring higher education in colleges and universities. This strand of the literature has focused on finding the growth-enhancing allocation of investment between the two stages. Yet it usually refrains from introducing into its models the skill-bias nature of economic growth in general, and capital-skill complementarity in particular. In this study I introduce capital-skill complementarity into a hierarchical education framework. This assumption seems natural, as

I would like to thank two anonymous referees and an associate editor for their useful comments. I am thankful to Itzhak Zilcha, Joseph Zeira, Daniel Tsiddon, and participants of the seminar at the Department of Economics, University of Haifa for their helpful suggestions. Address correspondence to: Assaf Sarid, Department of Economics, University of Haifa, 199 Aba Khoushy Avenue, Mount Carmel, Haifa 3498838, Israel; e-mail: asarid@econ.haifa.ac.il. 
different stages of education lead to different skills. I show that some of the results and policy implications obtained in previous studies in the hierarchical education literature change qualitatively once the assumption of capital-skill complementarity is introduced.

The literature on investment in a hierarchical education system and its implications for growth emerged in 2002 with the pioneering study of Driskill and Horowitz (2002), which was followed by others. Instead of focusing on the optimal magnitude of investment in education, these studies focused on the optimal allocation of investment at different stages of growth. These studies usually suggest some policy implications, which emerge naturally from their theoretical analysis. However, they usually do not embed in their analysis physical capital in general and capital-skill complementarity in particular. This last assumption is important for policy implications for several reasons. Most importantly, the incentives, either private or social, for investment in different factors of production depend on the marginal rate of return, which in turn depends both on their relative scarcity and on the scarcity of their substitutes and complements. As a result, any analysis that attempts to find a growth-enhancing policy that does not take into account all factors of production and their interrelations may offshoot its target. Furthermore, physical capital and human capital compete over the resources in their formation. Consequently, policy implications that include only one factor of production neglect the crowding-out effect on the other, and therefore may be misleading.

In the following I discuss my results in detail, but let me present for now two examples of results in the hierarchical education literature that are changed once capital-skill complementarity is introduced. First, in Driskill and Horowitz (2002), the authors show in a neoclassical growth model that the growth-enhancing composition of a social planner between basic education and higher education depends on the stage of development of the economy. They argue that poorer countries should invest more in higher education than in basic education, as the former is less abundant than the latter, and hence the return to investment for the former is higher than for the latter. On the other hand, previous growth accounting exercises [Gemmell (1995)] argue that in poorer countries basic education contributes to growth more than higher education, whereas in richer countries it is higher education that contributes more to growth. ${ }^{1}$ The policy implication of this exercise is that a government of a poorer country should invest more in basic education-rather than in higher education-as Driskill and Horowitz (2002) suggest.

This puzzle can be resolved by adding the assumption of capital-skill complementarity, as my first result shows: for any partition of the labor force into basically educated and highly educated labor, when physical capital is scarce, the return to investment in higher education is relatively low (because its complement is scarce), whereas the return to investment in basic education is relatively high (because its substitute is scarce). Because the contribution to growth and the rate of return are closely related, when physical capital is scarce, investment in basic education contributes more to growth than investment in higher education. 
Second, in previous studies in the hierarchical education system, the goal of subsidizing higher education is to increase the rate of enrollment in higher education, and once all individuals acquire higher education, there is no economic justification for such a subsidy. Note, however, that once physical capital is introduced, this result may not hold true, as subsidizing higher education may increase disposable income and savings, and hence accelerate growth. Hence, once again, introducing physical capital in general, and capital-skill complementarity in particular, plays a key role in understanding the policy implications within the hierarchical education framework.

The analysis is carried out using an overlapping-generations (OLG) model in which individual choices endogenously determine the accumulation of physical and human capital. Ex ante homogeneous individuals live for two periods. During the first period, each individual obtains basic education for free, and may also choose to invest in higher education at a cost. Higher education rewards the individual with higher wages during the second period of life. In this period the individual works, consumes, and gives birth to one offspring. Each individual derives utility from consumption and from the bequest he makes to his offspring. Thus, he has two decisions to make: in the first period whether to invest in higher education or not, and in the second period how to allocate his resources between consumption and the bequest. The aggregate bequests constitute the resources invested both in physical capital and in higher education.

I take the standard and most basic assumption of the hierarchical education literature, according to which the production of higher education uses as input the output of the K-12 system; i.e., the larger the amount of basic education, the higher the productivity of investment in higher education. The government imposes an income tax on highly educated workers, fully finances basic education, and may also subsidize tuition in higher education.

I now discuss in detail the results obtained in this study. The first result springs from using growth-accounting methodology, which enables me to show that at earlier stages of development basically educated labor contributes more to growth than highly educated labor, and that later on, as the economy develops and human capital is accumulated, the opposite is the case. This fits the empirical growth accounting exercises performed by Gemmell $(1995,1996)$, and as described in the preceding, may bridge the gap between previous policy results obtained by Driskill and Horowitz (2002).

This result springs from introducing capital-skill complementarity into a hierarchical education framework. Capital-skill complementarity implies that highly educated workers complement physical capital and basically educated workers, whereas physical capital and basically educated workers are substitutes. ${ }^{2}$ This implies that for any given partition of the labor force into basically educated and highly educated workers, the greater the physical capital stock, the higher the marginal productivity of highly educated labor, and the lower the marginal productivity of basically educated labor. Therefore, at the outset of the development process, when the stock of physical capital is relatively small, the marginal 
productivity of highly educated workers is accordingly low, whereas the marginal productivity of basically educated workers is accordingly high. This is the first reason for the dominance of basically educated workers in the contribution to growth at this stage. In addition, at this stage, because of low income, investment in higher education is relatively low, and therefore basic education is more abundant. This too contributes to the dominance of basically educated workers in their contribution to growth. As the economy develops, the opposite occurs, through the sufficient accumulation of physical capital. Hence, capital-skill complementarity yields a Gemmell-like pattern of contribution to growth.

Capital-skill complementarity leads to the next result, according to which even if all individuals acquire higher education, the growth-enhancing policy still calls for subsidizing higher education. This result contradicts those of previous studies in the literature, such as Blankenau et al. (2007). In these studies, the purpose of such a subsidy is to increase the enrollment rate in higher education. Nevertheless, its downside is that it comes at the expense of investment in basic education, which in turn lowers the productivity of all workers. If all individuals acquire higher education in the first place, the overall effect on growth is negative, as enrollment cannot increase. In my model, an additional positive effect of the subsidy on economic growth is at work: the net cost of investment in higher education is lower, which frees additional resources for private investment in physical capital. This, in turn, may stimulate economic growth.

I next turn to find numerically the optimal sequence of education allocation policies. Because I assume homothetic preferences, maximizing utility implies maximizing output. The analysis shows that at earlier stages of development all funds should be allocated to the school system; as the economy develops the funds allocated to higher education should be gradually increased. Note that this result contradicts the result obtained in Driskill and Horowitz (2002), and the reason is the introduction of capital-skill complementarity. It is, however, consistent with the results of the dynamics of the contribution to growth by the various factors of production stated in the preceding. In earlier stages of growth, basically educated labor contributes more to growth than highly educated labor, whereas in later stages the opposite is the case. A government that wishes to enhance economic growth should allocate more resources to producing the factor of production that has a larger effect on growth. Thus, at earlier stages of development this means allocating more resources to the school system and, as the economy develops, resources should be shifted gradually to producing highly educated workers.

The final result of the paper analyzes the dynamics of human capital accumulation along its transitional path toward the steady state. This is a novel analysis, as most previous studies in the hierarchical education literature analyzed only steady state characteristics. I show that along the growth path, the enrollment rate in higher education takes on an $\mathrm{S}$ shape. The economic logic behind this result is as follows: At the beginning of the development process, both highly educated labor and physical capital are scarce. Because of capital-skill complementarity, 
at the margin, the marginal productivity of physical capital is finite (because it has a substitute: basically educated workers), whereas the marginal productivity of highly educated workers, and hence the marginal return to investment in higher education, is infinite. Consequently, most of the resources that fund investment are allocated to forming highly educated labor. As highly educated labor accumulates, its marginal productivity declines (and so does the marginal return to investment in higher education), but the marginal productivity of physical capital increases (because of capital-skill complementarity). At a certain point in time, investment in physical capital becomes profitable, and some of the resources that fund the investment in higher education shift to fund the investment in physical capital. Because physical capital and higher education are complements (because of capital-skill complementarity), this yields a rise in the rate of return to investment in higher education, and hence investment in higher education increases as well. This yields the convexity of the S-curve. At later stages, the marginal return to investment in higher education declines because of diminishing marginal productivity, which yields the concavity in the final stage of development and completes the S-curve. This result seems to fit the data of the $S$-shaped pattern of tertiary education in the United States, as well as other OECD countries, as shown in the following.

\section{LITERATURE REVIEW}

As discussed in Section 1, this paper attempts to fill in the gap between two strands in the literature: The one that explores how investment in a hierarchical education system affects economic growth, and the skill-bias nature of growth. Both of these strands of the literature are well established, as I demonstrate in the following.

The hierarchical education literature explores how the allocation of resources in education, as opposed to the total resources allocated, affects growth. In a pioneering work, Driskill and Horowitz (2002) constructed a standard growth model to analyze the optimal timing of investment in human and physical capital, where human capital is characterized by a hierarchical structure. In their model, a central planner decides when to invest in physical and human capital and it is shown that the decision depends upon the relative scarcity of physical capital. Although their research includes both physical and human capital, their construction of a central planner analysis does not leave room for understanding the underlying forces that affect private investment in education systems, and hence their study sheds no light on the policy implications for a decentralized economy. ${ }^{3}$

Driskill and Horowitz (2002) was followed by Su (2004), Blankenau (2005), Blankenau et al. (2007), Arcalean and Schiopu (2010), and Viaene and Zilcha (2013). Su (2004) uses a successive-generations model with heterogeneity in pre-schooling preparation to explore how public spending on education affects inequality. In her model, each individual acquires human capital in a hierarchical education system and then supplies efficiency units to the labor market. The government finances both types of human capital and the quality of each type is an increasing function of the funds allocated to it. She finds that there exists a 
lower bound for investment in basic education and that the allocation of funds between the two types of education affects both efficiency and equality, usually with opposite signs. In her model, however, she assumes that the two types of workers are perfect substitutes, an assumption that is not supported by empirical evidence, as discussed in the following.

Blankenau (2005) and Blankenau et al. (2007) analyze the effect of investment in the two types of human capital on output, growth, and welfare. Blankenau (2005) provides an OLG model in which homogeneous individuals acquire basic education in a compulsory education system and may also acquire higher education. The government provides the compulsory education free of charge and may subsidize higher education. The production process does not involve physical capital. He shows that in the early stages of development growth is maximized if all resources are allocated to the $\mathrm{K}-12$ system. He also shows that at later stages of development the government should allocate some funds to subsidizing higher education in order to maximize growth. Furthermore, once all individuals acquire higher education, there is no justification for the subsidy, because its purpose is merely to increase the enrollment rate in higher education. In the model presented in this paper, I show that his results are valid only in the absence of physical capital and may not be consistent with the capital-skill complementarity evidence.

Physical capital is still absent in Blankenau et al. (2007), although heterogeneity in ability is introduced to Blankenau (2005). They show how innate ability affects individuals' preferences over the optimal allocation of public funds to the education system. Although their analysis sheds light on the political economy of education and adds validity to the results obtained in Blankenau (2005), they analyze only a steady state, whereas the present model analyzes the dynamics of transition toward the steady state as well. ${ }^{4}$

Arcalean and Schiopu (2010) construct an OLG model and explore how private and public spending on education in a hierarchical education system affect growth. In their model, public and private inputs are substitutes in production and individuals are homogeneous. They show that to maximize growth most of the public resources should be devoted to the school system. Although similar issues are explored here, none of the previous studies considered - at least not explicitlythe impact of capital-skill complementarity, as documented by Griliches (1969) and Goldin and Katz (1998). Furthermore, they do not analyze the dynamics of factor accumulation that arises from public investment in education.

The rest of this paper is organized as follows: Section 3 presents the model and Section 4 analyzes its equilibrium. Section 5 analyzes the contribution to growth of each type of education, Section 6 analyzes policy implications of the model, and Section 7 concludes.

\section{THE MODEL}

Consider a closed overlapping-generations economy with a constant population normalized to unity. In every period the economy produces a single homogeneous 
good that can be either consumed or invested. The good is produced using physical capital and two types of labor: basically educated and highly educated. The savings in each period are used for investment in both physical and human capital, both endogenously determined. Each individual lives for two periods: a learning period followed by a working period. In the learning period, each individual acquires basic education and may acquire higher education as well. In the second period each individual works, consumes, and gives birth to one offspring, to whom he gives a bequest. The economy starts at period $t=0$ with initial endowments of all factors of production, with a generation in the working period and another generation in the learning period.

\subsection{Production and Factor Prices}

Production occurs within a period using technology similar to that described by Maoz and Moav (2004) and satisfies the findings of Griliches (1969) and others; i.e., highly educated labor is complementary to physical capital and basically educated labor, and physical capital and basically educated labor are perfect substitutes: ${ }^{5}$

$$
Y_{t}=A E_{t}^{1-\alpha}\left(K_{t}+U_{t}\right)^{\alpha}=A E_{t} z_{t}^{\alpha}, \quad z_{t} \equiv \frac{K_{t}+U_{t}}{E_{t}}
$$

where $Y_{t}$ represents output in period $t, K_{t}$ is the amount of physical capital in period $t$, and $E_{t}$ and $U_{t}$ denote the quantity of efficiency units of highly educated labor and basically educated labor, respectively, supplied in the labor markets.

Factor markets are competitive, and given factor prices, producers choose the amounts of physical capital, basically educated labor, and highly educated labor to maximize profits. The producers' inverse demand for the factors of production is therefore

$$
w_{t}^{E}=(1-\alpha) A z_{t}^{\alpha}
$$

and

$$
w_{t}^{U}=R_{t}=\alpha A z_{t}^{\alpha-1},
$$

where $w_{t}^{E}$ and $w_{t}^{U}$ are wages per efficiency unit of highly educated and basically educated labor, respectively, and $R_{t}$ is the rental rate of capital in period $t$.

\subsection{Individuals}

Individuals live for two periods and ex ante are homogeneous. In the first period, each individual acquires a basic education, which is compulsory and provided by the government. ${ }^{6}$ After acquiring basic education, each individual may acquire higher education as well. An individual who does not acquire higher education moves on to the second period of life, during which he inelastically supplies efficiency units to the labor market and is employed as a basically educated worker. An individual who acquires higher education pays a tuition fee. Following 
Blankenau (2005) and Blankenau et al. (2007), I assume that after graduating, a worker with higher education moves to the second period of life, during which he inelastically supplies efficiency units both as a basically educated worker and as a highly educated worker. This assumption provides tractability and captures the idea that many jobs that require higher education include tasks that do not. ${ }^{7}$ During the second period of life, all individuals work, consume, and give birth to one offspring, to whom they give a bequest.

I follow Zilcha (2003) and many others in assuming that agents are altruistic. In other words, their utility depends not only on their consumption, but also on the bequests they give to their offspring. Each individual $i$ derives utility from consumption in period $t, c_{t}^{i}$, and from the intergenerational transfer to his offspring, $b_{t+1}^{i}$, according to the following utility function:

$$
u_{t}^{i}\left(c_{t}^{i}, b_{t+1}^{i}\right)=(1-\beta) \log c_{t}^{i}+\beta \log b_{t+1}^{i},
$$

where $0<\beta<1$ and $\beta$ is assumed to be equal across individuals and generations.

Education. All individuals acquire basic education according to the following production function:

$$
\phi_{t+1}^{i}=\left(q_{t}\right)^{\gamma}
$$

where $\phi_{t}^{i}$ represents the efficiency units of a basically educated worker $i$ at period $t$ and $q_{t}$ represents the resources the government allocates to the school system, $0<\gamma<1.8$ This stage of education is compulsory and fully financed by the government. The production function is similar to the one used in Restuccia and Urrutia (2004), Su (2004), and Blankenau et al. (2007). Only Restuccia and Urrutia (2004) define $q_{t}$ as the sum of public and private expenditures on basic education, a feature that enables them to examine the intergenerational persistence of earnings, which is a consequence of parental investment in education. ${ }^{9}$ After graduating from the compulsory school system, individuals can choose to acquire higher education. The production function of higher education is given by

$$
e_{t+1}^{i}=B \phi_{t+1}^{i}
$$

where $B>0$. This production function is common in the hierarchical education literature and is similar to the one used by Blankenau et al. (2007) and Viaene and Zilcha (2013). It differs from Blankenau et al. (2007) in one aspects: they introduce heterogeneity in innate ability during this stage of education. There is a resource cost for acquiring higher education in the form of a tuition fee, $h$, which may be (partially) subsidized by the government. The subsidy rate in period $t$ is denoted by $\eta_{t}$.

Income. An individual who does not acquire higher education supplies his efficiency labor units inelastically. The income of basically educated individual $i$ is given by

$$
y_{t}^{i, U}=w_{t}^{U} \phi_{t}^{i}+R_{t} b_{t}^{i}
$$


The income of a highly educated individual is given by

$$
y_{t}^{i, E}=w_{t}^{U} \phi_{t}^{i}+(1-\tau) w_{t}^{E} e_{t}^{i}+R_{t}\left[b_{t}^{i}-\left(1-\eta_{t}\right) h\right]
$$

I assume that the tax rate $\tau$, which is imposed on the income component that is unique to the highly educated labor, is constant across individuals and time. In contrast to Blankenau et al. (2007), the income tax is proportional, rather than a lump-sum tax, which is regressive by definition. Note that income is the sum of three components: the efficiency units he supplies as a basically educated worker, the efficiency units he supplies as a highly educated worker and the net bequest he receives from his parent (after paying the tuition fee for higher education). ${ }^{10}$

The individual's optimization. Each individual maximizes the utility function given by (4) subject to the following budget constraint:

$$
c_{t}^{i}+b_{t+1}^{i}=y_{t}^{i, j}
$$

where $j \in\{E, U\}$, according to the level of education he chooses. Each individual has two decisions to make: during the learning period he decides whether or not to acquire higher education and during the working period he allocates resources between consumption and the bequest. Because the utility function as given by (4) is separable, I first calculate the optimal levels of consumption and bequest as functions of income and then solve the education decision. It is straightforward that the optimal levels of consumption and bequest are given, respectively, by

$$
c_{t}^{i *}=(1-\beta) y_{t}^{i, j}
$$

and

$$
b_{t+1}^{i *}=\beta y_{t}^{i, j} .
$$

Note that maximizing utility is equivalent to maximizing income. Thus, individuals acquire higher education as long as the net income of a highly educated worker [as given by (8)] is at least as high as that of a basically educated worker [as given by (7)]. Using these equations, this condition can be expressed using the following inequality, which holds true for individuals who acquire higher education:

$$
\frac{(1-\tau) w_{t+1}^{E} \cdot e_{t+1}^{i}}{R_{t+1}} \geq\left(1-\eta_{t}\right) h .
$$

Inequality (12) suggests that individuals acquire higher education as long as its cost is not greater than the present value of its return. Note that for a given subsidy, the right-hand side of (12) is constant. However, as more individuals acquire higher education, the skill premium declines (because of diminishing marginal productivity). Two cases will be considered. In the first, the wage per efficiency unit of highly educated labor is such that the present value of the income due to higher education is greater than the cost of higher education, even when all individuals acquire it. Obviously, all individuals acquire higher education in this 
case and (12) becomes a strict inequality. In the second case, for a certain amount of efficiency units, the wage per highly educated efficiency unit is such that the present value of acquiring higher education is equal to its cost. This implies that all individuals are indifferent to acquiring higher education and (12) becomes a strict equality. In this case, only some individuals acquire higher education. Let $\lambda_{t}$ denote the enrollment rate in higher education in period $t$. Therefore, $\lambda_{t}=1 \mathrm{in}$ the first case and $\lambda_{t}<1$ in the second. ${ }^{11}$

\subsection{The Government}

In each period, the government levies a flat income tax on highly educated labor and uses the revenue to fund the school system and to subsidize tuition fees. I assume that the tax rate is exogenously given and constant over time and that the government maintains a balanced budget in each period. Note that the income share of highly educated labor is given by $1-\alpha$. Hence the quality of schools is given by

$$
q_{t}=\theta_{t} \tau(1-\alpha) Y_{t},
$$

and the subsidy rate is given by

$$
\eta_{t}=\frac{\left(1-\theta_{t}\right) \tau(1-\alpha) Y_{t}}{\lambda_{t} h}
$$

where $\theta_{t}$ is the allocation policy parameter, which is exogenously given at this stage of the analysis. (In Section 6 this parameter will be determined endogenously.) Note that the numerator of the right-hand side of (14) is the total public expenditure on higher education, whereas the denominator is the total expenditure on higher education (both private and public). The subsidy rate is given by the ratio of these expressions.

\subsection{The Dynamics of the Factors of Production}

With the next-period factor prices and government allocation policy parameter, $\theta_{t}$, given, the aggregate quantities of the two types of labor can be written as functions of the enrollment rate, $\lambda_{t}$, and the present period's output:

$$
E_{t+1}=\lambda_{t} e_{t+1}^{i}=\lambda_{t} B \cdot\left[\theta_{t} \tau(1-\alpha) Y_{t}\right]^{\gamma}
$$

and

$$
U_{t+1}=\left[\theta_{t} \tau(1-\alpha) Y_{t}\right]^{\gamma}
$$

The dynamics of physical capital. Note that the aggregate saving in the model is generated by the bequests from the parents to their offspring. Savings finance investment in both physical capital and human capital (in the form of higher education). Hence, the investment in physical capital is equal to the period's total 
bequests minus the private resources devoted to acquiring higher education:

$$
K_{t+1}=\beta[1-\tau(1-\alpha)] Y_{t}-\left(1-\eta_{t}\right) h \cdot \lambda_{t} .
$$

\section{DYNAMIC EQUILIBRIUM}

DEFINITION 1. Given the initial endowments of factors of production, $K_{0}, U_{0}$, and $E_{0}$, and the government policy, $0<\tau<1$ and $0 \leq \theta_{t} \leq 1$, a competitive equilibrium in this economy is a sequence of consumption-bequest allocations, $\left\{c_{t}, b_{t+1}\right\}_{0}^{\infty}$; enrollment rates, $\left\{\lambda_{t}\right\}_{0}^{\infty}$; stocks of factors of production, $\left\{K_{t}, E_{t}, U_{t}\right\}_{0}^{\infty}$; and factor prices, $\left\{w_{t}^{U}, w_{t}^{E}, R_{t}\right\}_{0}^{\infty}$, such that

(a) Each individual in each generation maximizes his utility according to (4), (9), (10), and (11);

(b) $\lambda_{t}$ is determined according to the education acquisition condition given by (12);

(c) factor prices are determined according to (2) and (3);

(d) government expenditures satisfy (13) and (14);

(e) factors are accumulated according to (15), (16), and (17); and

(f) factor and goods markets clear.

The following lemma states that in this economy competitive equilibrium is uniquely determined and the next lemma states that under plausible assumptions on the parameter values the economy converges to a unique steady state. These lemmas enable me to analyze the dynamics of the economy in the remainder of the paper.

LEMMA 1. For any initial values of $K_{0}, U_{0}$, and $E_{0}$ and for any government policy $0<\tau<1$ and constant $\theta$, there exists a unique competitive equilibrium.

Proof. Equations (13) and (14) are satisfied by definition. The subsidy in each period, as determined by (14), depends solely on the enrollment rate. This implies that the evolution of factors as described by (15), (16), and (17) depends solely on the enrollment rate. Note also that $c_{t}$ and $b_{t+1}$, as given by (10) and (11), are uniquely determined, given the individual's income, which in turn depends on the educational decision made by the individual in the previous period. The latter depends, as can be seen from (12), on market-clearing wages, which are determined uniquely by the enrollment rate. Hence, if the enrollment rate [condition (b)] is uniquely determined, conditions (a), (c), (d), (e), and (f) are satisfied in each period.

In each period, there are two possible equilibria: either all agents acquire higher education and hence the enrollment rate is uniquely determined $\left(\lambda_{t}=1\right)$ and (12) holds as a strict inequality, or not all agents acquire higher education, in which case (12) holds as an equality. Substituting wages as given by (2) and (3), the definition of $z_{t+1}$ as given by (1), the subsidy rate as given by (14), and $\lambda_{t}$ as given 
by (15) into (12) yields

$$
\begin{aligned}
\lambda_{t}= & \frac{(1-\tau)(1-\alpha)\left\{\beta[1-\tau(1-\alpha)] Y_{t}+\left[\theta_{t} \tau(1-\alpha) Y_{t}\right]^{\gamma}\right\}}{h[\alpha+(1-\alpha)(1-\tau)]} \\
& +\frac{\left(1-\theta_{t}\right) \tau(1-\alpha) Y_{t}}{h} .
\end{aligned}
$$

Consequently, $\lambda_{t}$ is uniquely determined and therefore so is equilibrium. ${ }^{12}$

LEMMA 2. For any government policy $\{\tau, \theta\}$ and initial endowments of factors of production $K_{0}, E_{0}$, and $U_{0}$, the corresponding equilibrium converges to a unique steady state.

Proof. Three stages of development will be considered: The stage in which investment in physical capital is zero; the stage in which the individuals who wish to acquire higher education constitute a certain proportion of generation $t$; and the stage in which all individuals in generation $t$ acquire higher education. I provide here an outline of the proof; the details of the proof appear in Appendixes A and $\mathrm{B}$.

At early stages of development, resources to invest in higher education and physical capital are scarce. It may be the case that investment in physical capital is equal to zero, ${ }^{13}$ and from (17) the enrollment rate equals

$$
\lambda_{t}=\frac{\beta[1-\tau(1-\alpha)]+\left(1-\theta_{t}\right) \tau(1-\alpha)}{h} Y_{t}
$$

Substituting (19) into (15) yields $E_{t+1}$ as a function of $Y_{t}$ alone. Note that $U_{t+1}$ is a function of $Y_{t}$ alone and that in this case $K_{t+1}=0$. Substituting into the production function yields a dynamic equation in which $Y_{t+1}=\Phi\left(Y_{t}\right)$. It is straightforward that this function is monotonically increasing. Hence, either the economy converges to a steady state at this stage of development, ${ }^{14}$ or $Y_{t}$ increases enough to enable positive investment in both physical capital and higher education. (Initial conditions may be such that this was already the case in the first place.) In this case, $0<\lambda_{t} \leq 1$. I first analyze the case of $\lambda<1$ and then the case of $\lambda_{t}=1$. When $\lambda_{t}<1$, its value is given by (18), using the condition for acquiring higher education, (12), which holds as an equality. Substituting this into (17) and (15) enables us to express all factors of production as functions of $Y_{t}$. Substituting these expressions into the production function yields $Y_{t+1}$ as an increasing and concave function of $Y_{t}$, and the economy converges to a unique steady state. ${ }^{15}$ If $\lambda_{t}=1$, it is straightforward to show that all factors of production depend solely on $Y_{t}$ and that the corresponding dynamic equation satisfies the Inada conditions. ${ }^{16}$

\section{CONTRIBUTION TO GROWTH}

This section analyzes the evolution of the contribution to growth made by each type of labor. I parameterize the model and analyze it numerically. The following 
parameter values were used: $\tau$ is set to 0.36 , which is the average total tax receipts in the OECD; $\theta_{t}$ is set to $0.76 \forall t$, which is the average share of public expenditure on education in the OECD allocated to the school system; $1-\alpha$, which represents the output share of highly educated labor, is set to $0.4 ;{ }^{17}$ following Blankenau et al. (2007), $\gamma$ is set to 0.12 ; and the saving rate is set to 0.2 . The values for the other parameters are presented in Appendix C, as well as the ranges I use for robustness checks. Interestingly, the model does a good job in predicting that about $45 \%$ of the labor force will acquire higher education in the steady state, which is close to the OECD average of $44 \%$.

\subsection{Contribution to Growth}

The following proposition shows that at earlier stages of development, basically educated labor accounts more for growth than highly educated labor, whereas at later stages of growth the situation is reversed. Several steps are required to demonstrate this phenomenon. First, the growth rates of output, basically educated labor, and highly educated labor are calculated. Second, the growth accounting methodology is used to calculate what proportion of the output growth rate can be accounted for by the accumulation of each type of human capital.

By fully differentiating the production function, dividing by $Y_{t}$, and using the competitiveness of factor markets, we obtain the following:

$$
g_{y}=(1-\alpha) g_{E}+\alpha \frac{U_{t}}{K_{t}+U_{t}} g_{u}+\alpha \frac{K_{t}}{K_{t}+U_{t}} g_{K},
$$

where $g_{x} \equiv \frac{\Delta x_{t}}{x_{t}}$. I then numerically analyze (20). The contribution of highly educated labor to growth is given by the term $(1-\alpha) g_{E}$, whereas the contribution of basically educated labor is given by $\alpha \frac{U_{t}}{K_{t}+U_{t}} g_{u}$. Figure 1 presents an example in which $\alpha \frac{U_{t}}{K_{t}+U_{t}} g_{u}>(1-\alpha) g_{E}$ during earlier stages of development and $\alpha \frac{U_{t}}{K_{t}+U_{t}} g_{u}<(1-\alpha) g_{E}$ during the more advanced stages.

PROPOSITION 1. For some parameter values, basically educated labor contributes more to growth than highly educated labor at the early stages of development; at later stages of development, the opposite is the case.

Proof. See Figure 1.

Figure 1 provides an example in which basically educated labor accounts for growth more than highly educated labor as earlier stages of growth, and the opposite is the case at later stages. My numerical analysis shows that this result is robust. ${ }^{18}$ This result may provide a theoretical explanation for the empirical growth accounting results obtained by Gemmell (1995, 1996), who performs a growth accounting exercise for both developed and developing countries, in which he measures three types of human capital: basic, intermediate, and high. His proxies for these types of human capital are the percentages of the population with primary, 


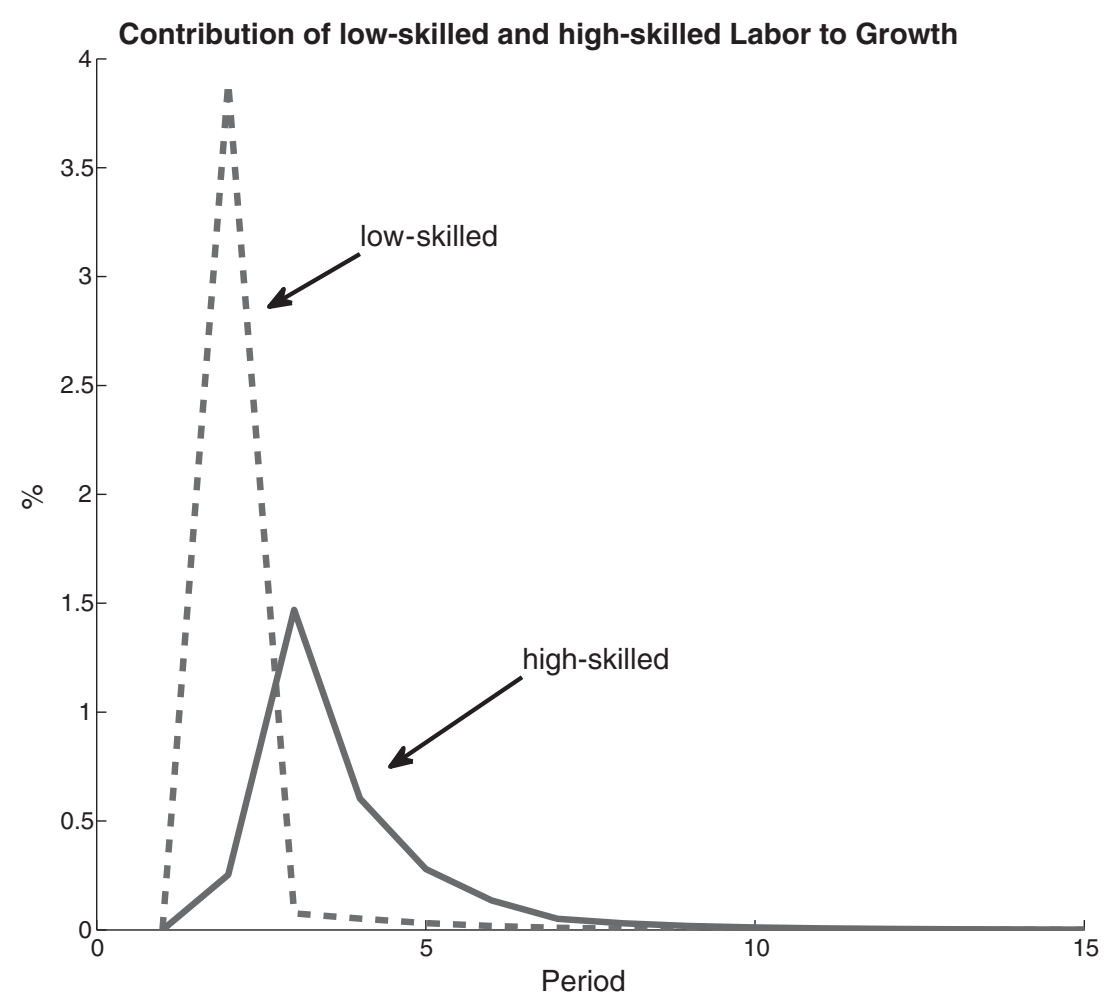

FIGURE 1. Growth accounting. At the beginning of the development process, it is basically educated labor that accounts more for growth; at later stages of development, it is highly educated labor that accounts more for growth.

secondary, and tertiary education, respectively. He finds that in the least developed countries, primary education accounts for growth more than the other two types of education; in developing countries, secondary education accounts for growth more than the other two types of human capital; and in developed countries, it is tertiary education that accounts for growth more than the other types of human capital. In the example shown, the economy converges to a unique steady state with $\lambda_{t}<1$. The numerical analysis shows that not only does the proposition hold as well for the case in which $\lambda_{t}=1$, but also that the switching point at which highly educated labor begins to contribute more to growth always occurs before all agents acquire higher education, as in Gemmell (1995).

This result stems from capital-skill complementarity. Recall that the assumption of capital-skill complementarity implies that physical capital complements highly educated workers and substitutes basically educated workers. Hence, for any given partition of the labor force into highly educated and basically educated labor, the greater the physical capital stock, the lower the marginal productivity 
of basically educated workers, and the higher the marginal productivity of highly educated workers. At earlier stages of development, the stock of physical capital is relatively low, and hence the marginal productivity of highly educated labor is low as well (and hence, its contribution to growth). At the same time, the marginal productivity of basically educated labor is high, and so is its contribution to growth. As the economy develops, physical capital is accumulated, which in turn increases the marginal productivity (and hence contribution to growth) of highly educated labor, and decreases the marginal productivity (and hence contribution to growth) of basically educated labor.

This process is even stronger because at earlier stages of growth, the supply of savings is low, and therefore investment in higher education and physical capital is low. As a result, the contribution of highly educated workers to growth is low. The marginal return to public investment in the school system, on the other hand, is high. Consequently, the growth rate of basically educated labor is relatively high, and so is its contribution to growth. As the economy develops, both basically educated labor and physical capital are accumulated, yielding a higher incentive for investment in higher education. Hence, highly educated labor grows at a higher rate, and its contribution to growth increases as well, overcoming the contribution of basically educated labor to growth, which itself declines, because of diminishing marginal return to public investment in the school system.

Note that this result is similar to that of Galor and Moav (2004), according to which human capital is replacing physical capital as the main engine for growth throughout the development process. In this model, basically educated labor is a substitute for physical capital, and therefore when basically educated labor contributes more to growth than highly educated labor, this can be interpreted as physical capital being the main engine of growth. However, after a few periods, it is highly educated labor that contributes more to growth, suggesting that human capital [in the terms of Galor and Moav (2004)] becomes the main engine for growth at the expense of physical capital.

\section{POLICY ANALYSIS}

The model thus far has presented the contribution to growth, given that the allocation policy parameter, $\theta_{t}$, is exogenous and constant over time. In this section, this assumption is relaxed and I analyze the effect of government policy on individuals' education decisions, the composition of the labor force, and output growth. Interestingly, an increase in $\theta_{t}$ affects the economy through several channels: First, an increase in $\theta_{t}$ affects the enrollment rate directly but with two opposing effects. On the one hand, higher $\theta_{t}$ implies that for a given flat tax rate, greater resources are devoted to the school system and therefore more efficiency units of basically educated labor are produced. Consequently, because of the form of the production function of higher education, this also implies that more efficiency units of highly educated labor are supplied by those who acquire higher education. As a result, the wage gap between basically and highly educated workers widens, which in turn 
implies that the enrollment rate rises as $\theta_{t}$ increases. On the other hand, a higher $\theta_{t}$ implies that acquiring higher education now requires a larger private investment, because the subsidy of the tuition fee is now smaller and thus the enrollment rate declines. Second, a change in $\theta_{t}$ also affects output indirectly through its impact on physical capital formation, which depends on the private resources devoted to acquiring higher education recall (17)]. When these resources increase, the investment in physical capital decreases. The former depends on the change in the enrollment rate and in the cost of tuition. Hence, an increase in $\theta_{t}$ may either increase or decrease the stock of physical capital.

The following propositions state how a change in $\theta_{t}$ affects the composition of the labor force and describe implications for output growth. Although previous studies in the hierarchical education literature have dealt with the impact of a change in $\theta_{t}$ on the enrollment rate, they have not dealt with the impact of such changes on physical capital. Introducing physical capital into the model, as I do here, changes some of the results from previous studies, as I show later. ${ }^{19}$

The following proposition demonstrates that even when all agents acquire higher education, a government that wishes to maximize output in the next period should subsidize higher education. This result differs from those obtained by Blankenau (2005) and Blankenau et al. (2007) and highlights the importance of physical capital in production. In their studies, physical capital was absent, and hence once all individuals acquired higher education, the subsidy to higher education had only a negative effect on growth, because it came at the expense of the quality of the $\mathrm{K}-12$ system. In this model, on the other hand, when all individuals acquire higher education, subsidizing higher education implies lowering private expenditure on higher education. This in turn increases the disposable savings that can be devoted to investment in physical capital. A decline in $\theta_{t}$ therefore implies a decline in the output of the school system, though also an increase in investment in its substitute, physical capital. As long as the marginal product of producing basic education is lower than the marginal product of forming physical capital, this change enhances economic growth. Let $\tilde{\theta}_{t}$ represent the allocation policy that maximizes output in period $t+1$. Then

PROPOSITION 2. Let $\lambda_{t}=1$. Then $\tilde{\theta}_{t}<1$ for some parameter values.

Proof. Differentiating next-period output with respect to $\theta_{t}$ gives

$$
\frac{\partial Y_{t+1}}{\partial \theta_{t}}=A z_{t+1}^{\alpha}\left\{(1-\alpha) \frac{\partial E_{t+1}}{\partial \theta_{t}}+\alpha z_{t+1}^{-1} \frac{\partial\left(K_{t+1}+U_{t+1}\right)}{\partial \theta_{t}}\right\} \text {. }
$$

The sign of the derivative of output with respect to $\theta_{t}$ as given by (21) depends on the sign of the term in the braces. Substituting the partial derivatives of the factors of production and yields an expression that is negative if

$$
\left(\tau Y_{t}\right)^{\gamma} \cdot(1-\alpha)^{\gamma-1} \leq\left\{\frac{\alpha \tau}{\gamma}-\beta[1-\tau(1-\alpha)]\right\} Y_{t}+h .
$$


Note that the left-hand side (LHS) of (22) is concave in $Y_{t}$, whereas the right-hand side (RHS) is linear. Note also that when $Y_{t}=0$, the LHS equals zero, whereas the RHS is strictly positive. This in turn implies that either the RHS is always greater than the LHS, and therefore the inequality always holds, or the equation has two solutions, and therefore the inequality holds only for some parameter values. ${ }^{20}$

The following corollary and proposition establish the next result, saying that maximizing the growth rate implies not maximizing the enrollment rate in higher education. In fact, maximizing growth usually implies shifting more funds to the school system than maximizing the enrollment rate does. Let $\Gamma \equiv\left[\frac{(1-\tau)(1-\alpha) \gamma}{\alpha+(1-\tau)(1-\alpha)}\right]^{1 /(1-\gamma)} ;$ then

COROLLARY 1. Given $\tau$, there is a unique $\theta_{t}$ that maximizes $\lambda_{t}$, in each period $t$, as given by $\theta_{t}^{*}=\Gamma \cdot \frac{1}{\tau(1-\alpha) Y_{t}}$ if $\Gamma \cdot \frac{1}{\tau(1-\alpha) Y_{t}}<1$. Otherwise, $\theta_{t}^{*}=1$.

Proof. Differentiating (18) with respect to $\theta_{t}$ and equalizing to zero yields

$$
\theta_{t}^{*}=\Gamma \cdot \frac{1}{\tau(1-\alpha) Y_{t}}
$$

It is straightforward that the second derivative is negative and hence the value obtained is a maximum point. Note that the value of $\theta_{t}^{*}$ is strictly positive and can be greater than one. In this case, we obtain a corner solution of $\theta_{t}^{*}=1$.

Corollary 1 states that in each period there is a unique value of the allocation policy parameter, $\theta_{t}$, that maximizes the enrollment rate. This result differs from the one obtained by Blankenau et al. (2007), according to which in the steady state the enrollment rate increases as the proportion of output used to subsidize higher education increases (in this model, this occurs as $\theta_{t}$ decreases). The reason for the existence of such an optimum point involves the two opposing forces that are at work. On the one hand, an increase in $\theta_{t}$ implies a greater quantity of efficiency units for both types of labor, and therefore the wage gap between basically and highly educated labor widens. The increased wage gap provides an incentive for more individuals to acquire higher education. On the other hand, a rise in $\theta_{t}$ implies a higher tuition fee, because an increase in $\theta_{t}$ implies that fewer public resources are devoted to higher education. As a result, the incentive for acquiring higher education decreases. These two forces work in opposite directions, and an optimum point exists where the two forces are in balance. Note also that $\theta_{t}^{*}$, which maximizes the enrollment rate as given by (23), is decreasing in $Y_{t}$. The reason for this is that, ceteris paribus, as output grows the enrollment rate also does [to see this, note that $\lambda_{t}$ as given in (18) is increasing in $Y_{t}$ ]. This in turn implies that for a constant $\theta_{t}$, the subsidy per student is lower, which implies a decrease in the enrollment rate. To offset this negative effect on the enrollment rate, the government should allocate more resources to higher education; i.e., it should decrease $\theta_{t}$. 
The following proposition states that the enrollment-maximizing policy is not necessarily identical to the policy that maximizes output growth in the next period. This proposition is similar to a result obtained by Su (2004), but contradicts other results obtained in the hierarchical education system literature [e.g., Patron and Vaillant (2012) and others].

PROPOSITION 3. If $\theta_{t}^{*}<1, \tilde{\theta}_{t}>\theta_{t}^{*}$; otherwise, $\tilde{\theta}_{t}=\theta_{t}^{*}=1$.

Proof. It is straightforward to show that $\frac{\partial E_{t+1}}{\partial \theta_{t}}=B\left[\theta_{t} \tau(1-\alpha) Y_{t}\right]^{\gamma}\left(\frac{\partial \lambda_{t}}{\partial \theta_{t}}+\frac{\lambda_{t} \gamma}{\theta_{t}}\right)$. When one substitutes $\theta_{t}^{*}$, which maximizes $\lambda_{t}$, into the equation, the left-hand expression in the brackets becomes zero (by the definition of $\theta_{t}^{*}$ ). Consequently, the derivative is positive. Next, note that $\frac{\partial K_{t+1}+U_{t+1}}{\partial \theta_{t}}>0$. Hence, the derivative $\frac{\partial Y_{t+1}}{\partial \theta_{t}}$ as given by (21) is positive.

Proposition 3 shows that maximizing the enrollment rate does not imply maximizing output. In fact, this proposition argues that as long as maximizing the enrollment rate requires that higher education be subsidized, maximizing output requires that the enrollment rate not be maximized. This result stems from introducing capital-skill complementarity into the model. Intuitively, maximization of the enrollment rate ignores the crowding-out effect of a change in $\theta_{t}$ on investment in physical capital. The allocation policy that maximizes enrollment channels more public resources to higher education, which in turn increases the enrollment rate. This, of course, comes at the expense of the quality of the K-12, and hence on the productivity of the higher education system. Yet maximizing enrollment affects growth through investment in physical as well; it has two opposing effects on the private expenditures on higher education. On one hand, the subsidy per student is greater, which decreases the net tuition fee per student. On the other hand, higher enrollment implies that more students pay the tuition fee, which in turn increases the private investment in higher education. The second force is the dominating one, and therefore the educational allocation policy that maximizes enrollment leads to an increase in private expenditure on higher education, which means that fewer resources are available for investment in physical capital. Because physical capital and highly educated labor are complements, underinvestment in physical capital reduces the marginal product of highly educated labor. These two effects on the productivity of highly educated labor affect the growth rate of output negatively. ${ }^{21}$

This result shows that the underlying assumption in Patron and Vaillant (2012) may not hold true. They analyze the education allocation policy that maximizes the ratio of highly educated labor to basically educated labor. They justify this assumption, because maximizing this ratio implies maximizing enrollment in higher education, which in turn implies maximizing growth. The result obtained here, then, may imply that this is not the case when capital-skill complementarity in particular, and the skill-bias nature of growth in general, are taken into account.

As stated earlier, this result is similar to the one obtained by Su (2004), and contradicts results obtained in the hierarchical education literature. This result relates also to the main result in Blankenau and Camera (2009). In their study, they 
show that maximizing productivity (and hence growth) does not imply maximizing enrollment, as this result shows. However, in their model, the result stems from the private information the agents have on their skills and the incentives they have for acquiring skills. In this study, on the other hand, the economic mechanism is different, as it stems from capital-skill complementary; policies that maximize enrollment do not take into account the decline in the quality of schools, and the possible decline in physical capital accumulation, and hence the decline in the productivity of highly educated labor and growth.

\section{Example: The policy path that maximizes next-period output}

Because of the complexity of the model, one cannot analytically calculate the sequence of $\tilde{\theta}_{t}$. For a numerical analysis, I assume that the government chooses the allocation policy parameter to maximize next-period output. There are several justifications for this assumption: First, because human capital must be produced in each period, there are no intergenerational externalities that individuals do not take into account when choosing whether or not to acquire higher education. Consequently, maximizing output in period $t+1$ in each period $t$ implies maximizing the sequence $\left\{Y_{t}\right\}_{0}^{\infty}$. Second, note that in this model, because the net income of all individuals is equal, and because maximizing income implies maximizing utility (on account of the logarithmic utility function), maximizing the total output of the economy implies maximizing the utility of all individuals in the next period. ${ }^{22} \mathrm{Fi}-$ nally, from a political economy point of view (which is not reflected in this model), a government may be myopic because it wishes to be reelected in the next period.

The numerical analysis shows that at the outset of the development process $\tilde{\theta}_{t}=1$; i.e., all public expenditures are devoted to the school system. After a few periods, $\tilde{\theta}_{t}$ gradually decreases and converges to its steady state value. Figure 2 depicts the results of this process. Tests of robustness confirm that the results are sound (the parameters used in the analysis are given in Appendix C, along with a range of parameters that were used for robustness checks.).

Note that at the early stages of development, output is maximized when all resources are devoted to the school system. There is a consensus with regard to this result in the literature. As the economy develops, the government gradually allocates more resources to higher education. The intuition behind this result is as follows: At the outset of the development process, all savings are devoted to finance tuition fees and hence there is no investment in physical capital. The government may increase investment in physical capital by subsidizing higher education. However, because basic education and physical capital are substitutes, and because the marginal product of producing basic education is higher than that of producing physical capital, it is optimal to invest all resources in the school system. As the economy develops, the marginal product of producing basic education decreases and hence there is a greater incentive to invest in physical capital by subsidizing higher education. Also note that for any constant $\theta_{t}, \lambda_{t}$ increases as the economy develops. A decline in $\theta_{t}$ accelerates the increase in the 


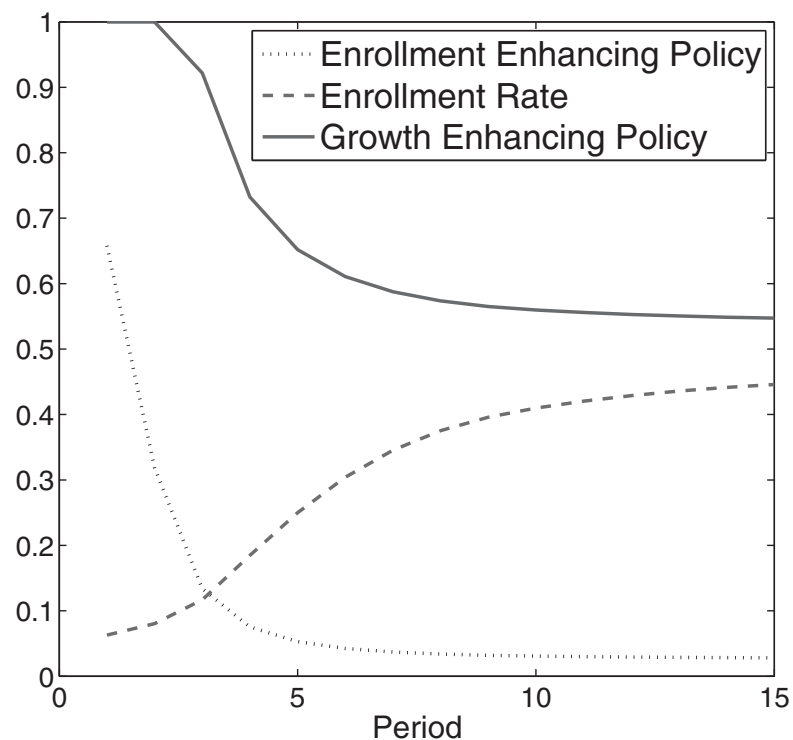

FIGURE 2. The trajectory of $\tilde{\theta}_{t}$. At the outset of development $\tilde{\theta}_{t}=1$ and then declines gradually.

enrollment rate and hence accelerates growth. Figure 2 shows that the results are similar to those obtained by Blankenau (2005) and Blankenau et al. (2007), yet their results analyze only the policy maximization along a balanced growth path, whereas the results here analyze also the transitional dynamics toward the steady state as well. The results differ, however, from Driskill and Horowitz (2002), who suggest investing in higher education rather than basic education at the early stages of development, with an emphasis on basic education in later stages of development.

Another explanation for this result is the contribution to growth of each factor of production at the various stages of development. As shown in Proposition 1, basically educated labor contributes more to growth than highly educated labor at the early stage of development. A government that wishes to maximize growth should then allocate more resources to producing basically educated labor than to producing highly educated labor. As the economy develops, highly educated labor starts to contribute more to growth, and therefore the government should shift resources from the less productive basically educated labor to the more productive highly educated labor. Hence, $\tilde{\theta}_{t}$ should decline over time.

\subsection{The Dynamics of Human Capital}

I now analyze another result that stems from the introduction of capital-skill complementarity. This result shows that for given government policy parameters, 


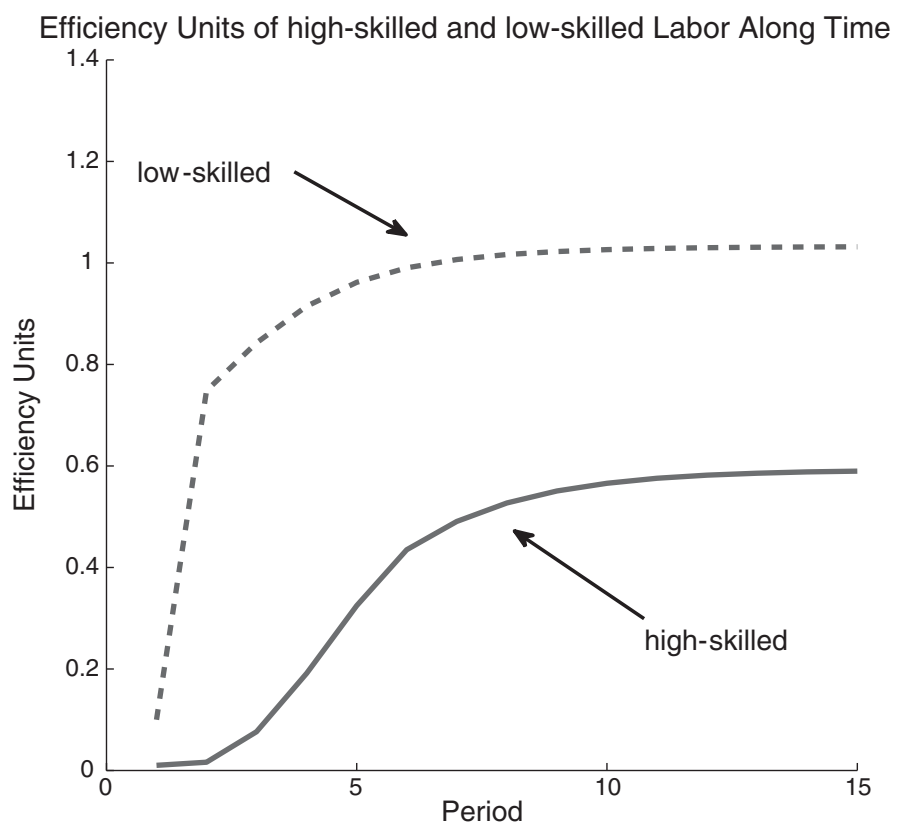

FIGURE 3. The evolution of the stocks of highly educated and basically educated labor.

$\{\tau, \theta\}$, the evolution of the enrollment rate takes on an S-shape. Figure 3 depicts the evolution of human capital over time. The horizontal axis displays time (in periods), whereas the vertical axis measures the quantity of efficiency units available of basically and highly educated labor. Basically educated labor evolves concavely, as is typical in growth models of this kind. As the economy grows, the government collects more taxes and thus allocates more funds to the school system; the concavity is a result of the diminishing marginal productivity in the production function of basic education, as given by (5). Note that the evolution of highly educated labor is described by an S-shaped curve: the quantity of highly educated labor rises slowly at first and then its growth rate accelerates for several periods; it subsequently continues to rise, but at a diminishing rate. This result seems to fit the data as presented in Figure 4.

Introducing capital-skill complementarity generates an inflection point that may explain this phenomenon. At the beginning of the development process, both highly educated labor and physical capital are scarce. Because of capitalskill complementarity, at the margin, the marginal productivity of physical capital is finite (because it has a substitute-basically educated workers), whereas the marginal productivity of highly educated workers, and hence the marginal return to investment in higher education, is infinite. Therefore most of the resources that fund investment are allocated to forming highly educated labor. This yields an increase in the stock of highly educated labor. As highly educated labor accumulates, 

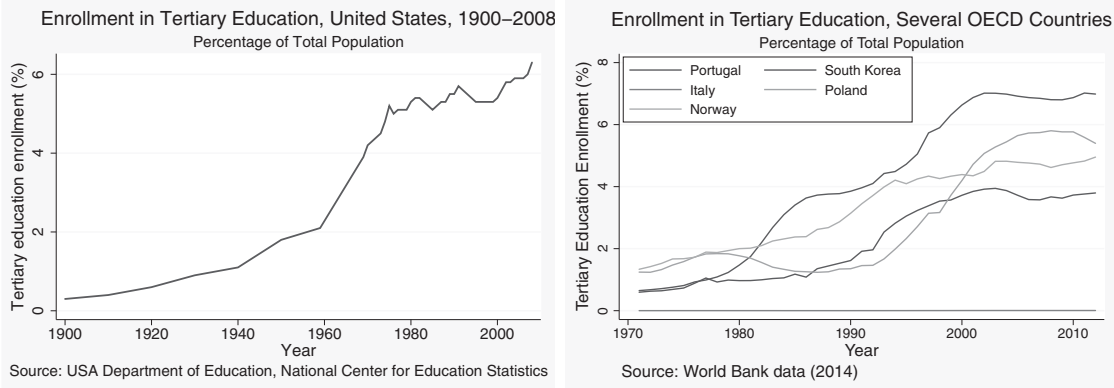

FIGURE 4. U.S. and other OECD countries' tertiary education enrollment is S-shaped.

its marginal productivity declines (and so does the marginal return to investment in higher education), but the marginal return to investment in physical capital increases (because of capital-skill complementarity). At a certain point in time, investment in physical capital becomes profitable, and some of the resources that fund the investment in higher education shift to funding the investment in physical capital. Because physical capital and higher education are complements (as a result of capital-skill complementarity), this yields a rise in the rate of return to investment in higher education, and hence investment in higher education increases as well. This yields the convexity of the S-curve. At later stages, the marginal return to investment in higher education declines because of marginal productivity, which yields the concavity at the final stage of development and completes the S-curve. The evolution of the enrollment rate along time is S-shaped as well, and for the same reasons, and is similar to the proportion of individuals who acquired higher education in the United States and other OECD countries during the twentieth century, as shown in Figure 4. The following proposition summarizes this result.

PROPOSITION 4. Let the initial endowments of factors of production be such that in early stages of development the enrollment rate evolves as described by (19). Then, for certain parameter values, the enrollment rate develops according to an S-shape over time.

Proof. Initial values are such that $\lambda_{t}$ applies to (19). Differentiating this equation with respect to $Y_{t}$ yields

$$
\frac{\beta[1-\tau(1-\alpha)]+\left(1-\theta_{t}\right) \tau(1-\alpha)}{h} .
$$

At a certain point, because of the increase in output and savings, investment in physical capital becomes profitable as well and $\lambda_{t}$ evolves according to (18). Differentiating this equation with respect to $Y_{t}$ yields

$$
\frac{(1-\alpha)\left[\beta(1-\tau)+\gamma\left(\theta_{t} \tau Y_{t}\right)^{\gamma-1}\right]+\left(1-\theta_{t}\right) \tau}{h} .
$$


Let $\tilde{Y}_{t}$ denote the output, in which the formation of the enrollment rate switches from (19) to (18). Then the S-shape occurs if at this point the value of (25) is greater than the value of (24). This is true if

$$
\tilde{Y}_{t}<\left\{\frac{(1-\tau)(1-\alpha)^{1+\gamma} \gamma\left(\theta_{t} \tau\right)^{\gamma}}{\alpha \beta[1-\tau(1-\alpha)]}\right\}^{\frac{1}{1-\gamma}}
$$

Hence, one can choose parameter values such that the inequality holds true.

As mentioned earlier, the implication of Proposition 4 is that the enrollment rate evolves in an S-shape pattern, similar to the pattern that is seen in the data, as shown in Figure 4. Figure 4 shows the share of the U.S. population enrolled in tertiary education over the course of the twentieth century, as well as in other OECD countries for 1970-2010. As can be seen, the path of the enrollment rate is S-shaped, which is the pattern also observed for only the student-age population and for only high school graduates. Note that this result stems from capital-skill complementarity. Consequently, previous theoretical studies in the hierarchical education literature, which do not include physical capital, may not generate this S-shaped pattern in the evolution of the enrollment rate. In this sense, this model may fit the data better than previous models in the hierarchical education literature.

\section{CONCLUSIONS}

The objective of this paper has been twofold: first, to bridge the gap between two strands in the literature: the hierarchical education system and the skill-biased nature of economic growth. Second, to analyze how educational policies affect economic growth. Unlike previous papers that have not incorporated physical capital into their models, I showed that capital-skill complementarity, which is supported by strong empirical evidence, is important in understanding economic growth patterns and education policies. I assume that highly educated labor is complementary to physical capital and to basically educated labor and that the government fully finances the school system and may subsidize higher education. The total saving in the economy is the source of private resources available for investment in physical and human capital. Hence, although highly educated workers and physical capital are complements in production, there is a resource constraint on investment in the formation of the two factors, and thus there is a tradeoff in investing in either one.

The model produces two sets of results. First, at the early stages of development, basically educated labor contributes more to growth than highly educated labor, whereas at later stages of development the situation is reversed. Second, the enrollment rate in higher education develops on an S-shaped curve. These two results spring from introducing capital-skill complementarity into a hierarchical education framework, and seem to fit the data. The second set of results relates to the effect of the dynamics of factors of production on allocation policies in education. 
These results differ from those in previous studies in the hierarchical education literature that have not introduced capital-skill complementarity into their models. Among these results, for example, I showed that even when all individuals acquire higher education, a growth-enhancing policy should subsidize higher education. This result also springs from capital-skill complementary and reverses previous results in the hierarchical education literature that do not employ this assumption.

The model uses a closed overlapping-generations framework with some specific assumptions. Hence, the issue of robustness is relevant. First, similar functional forms are in widespread use in the literature. Second, the functional forms are motivated by strong empirical evidence. The utility function is justified on both theoretical and empirical grounds, as suggested by Laitner (1997) and Zilcha (2003). The choice of the human capital production function is justified by empirical evidence showing that the quality of schools is determined by the quantity of public resources allocated to the school system. Furthermore, the fact that each type of human capital enters into the production function as a different factor of production is based on evidence that human capital produced in universities and colleges differs qualitatively from that produced in schools. The choice of the production function itself is based on the empirical evidence on capital-skill complementarity. Using a different production function that satisfies this assumption would change the results quantitatively but not qualitatively.

NOTES

1. One should note that growth accounting exercises do not show causation, as Aghion and Howitt (2007) argue.

2. These assumptions were first formulated within a production function by Griliches (1969).

3. Another study, which explores the hierarchical nature of investment in human capital using a social planner methodology, is Driskill et al. (2009). They show how the evolution of human capital in a hierarchical educational system is important in capturing the effect of human capital accumulation on economic growth. However, their paper, like many other papers in this strand of the literature, does not include physical capital and capital-skill complementarity, as this paper does.

4. Patron and Vaillant (2012) analyze policy implications in a theoretical model with a hierarchical education system. However, like Blankenau et al. (2007), their analysis sheds light only on the steady state, and does not include physical capital. Furthermore, they analyze the policy that maximizes the ratio between high-skilled to low-skilled labor, sincebecause they assume implicitly that the higher the ratio the higher the growth rate of the economy. In this paper I show that this assumption may not hold true because of the introduction of capital-skill complementarity.

5. Generally, the production function is of the form $Y_{t}=A \cdot E_{t}^{1-\alpha}\left(K_{t}+\sigma U_{t}\right)^{\alpha}$, where $\sigma$ denotes the measure of substitutability between the two factors of production. This would not change the results and would simply add more notation to the model.

6. Eckstein and Zilcha (1994) show the advantages of a compulsory school system. In fact, in most countries nowadays, acquiring at least a primary school education is compulsory.

7. Numerical analysis shows that the results do not change when each type of individual supplies a different type of human capital.

8. I implicitly assume here that the higher the resources allocated to the school system, the higher the quality of the school system, and hence the production function of basically educated labor increases in $q_{t}$. Card and Krueger (1990) provide the empirical support for this assumption by demonstrating a positive relationship between school resources and earnings. 
9. Su (2004) also introduces heterogeneity in the initial endowment of human capital into the production function.

10. Note that because the capital market is competitive, individuals can borrow funds to finance higher education. Consequently, the term in the square brackets can be negative.

11. The case of $\lambda_{t}=0$ is ruled out because the marginal product of highly educated labor is infinite as $E_{t} \rightarrow 0$.

12. As discussed later, there is also a possibility that the investment in physical capital equals zero. In this case, it is straightforward that $\lambda_{t}$ is uniquely determined.

13. At earlier stages of development, as both highly educated labor and physical capital are close to zero, the marginal product of highly educated labor is greater than that of physical capital, because of the substitutability between physical capital and basically educated labor.

14. Appendix A provides the parametric assumptions that ensure that there is no steady state in this case.

15. Appendix B provides the necessary conditions for the Inada conditions to be satisfied, and hence for the economy to converge to a unique steady state.

16. Unfortunately, because of the complexity of the model, I cannot analytically determine under what conditions the steady state includes an enrollment rate less than or equals to 1 .

17. The estimates of the share of output of highly educated labor used in the literature vary from 0.2 (Blankenau et al., 2007) to 0.5 (Caucutt and Kumar, 2003).

18. Appendix $C$ provides both the values of the parameters that I use in obtaining Figure 1, and the range of parameter values that I used for checking the robustness of this result.

19. For tractability issues, in this section I analyze merely the case in which initial endowments are such that $\lambda_{t}$ is given by (18), i.e., investment in physical capital is positive.

20. Reducing the tax rate when all individuals acquire higher education yields the same result, because it increases disposable income and thus savings, like the mechanism presented here.

21. Unfortunately, analyzing analytically $\tilde{\theta}_{t}$ is not possible due tobecause ofthe complexity of (21).

22. Another possible criterion for optimization may be the output in the steady state. This exercise is conducted in many papers, such as Blankenau (2005) and Blankenau et al. (2007). However, it neglects the inherent dynamic inefficiency in overlapping-generations models.

\section{REFERENCES}

Aghion, Philippe and Peter Howitt (2007) Capital, innovation, and growth accounting. Oxford Review of Economic Policy 23(1), 79-93.

Arcalean, Calin and Ioana Schiopu (2010) Public versus private investment and growth in a hierarchical education system. Journal of Economic Dynamics and Control 34(4), 604-622.

Barro, Robert (1991) Economic growth in a cross section of countries. Quarterly Journal of Economics 106(2), 407.

Blankenau, William (2005) Public schooling, college subsidies and growth. Journal of Economic Dynamics and Control 29(3), 487-507.

Blankenau, William and Gabriele Camera (2009) Public spending on education and the incentives for student achievement. Economica 76(303), 505-527.

Blankenau, William, Steven Cassou, and Beth Ingram (2007) Allocating government education expenditures across K-12 and college education. Economic Theory 31(1), 85-112.

Card, David and Alan Krueger (1990) Does School Quality Matter? Returns to Education and the Characteristics of Public Schools in the United States. Working paper 3358, National Bureau of Economic Research.

Caucutt, Elizabeth and Krishna Kumar (2003) Higher education subsidies and heterogeneity: A dynamic analysis. Journal of Economic Dynamics and Control 27(8), 1459-1502.

Driskill, Robert and Andrew Horowitz (2002) Investment in hierarchical human capital. Review of Development Economics 6(1), 48-58. 
Driskill, Robert, Andrew W. Horowitz, and Fabio M. Endez (2009) Hierarchical human capital and economic growth: Theory and evidence. Journal of Institutional and Theoretical Economics 165(4), 723-743

Eckstein, Zvi and Itzhak Zilcha (1994) The effects of compulsory schooling on growth, income distribution and welfare. Journal of Public Economics 54(3), 339-359.

Galor, Oded and Omer Moav (2004) From physical to human capital accumulation: Inequality and the process of development. Review of Economic Studies 71(4), 1001-1026.

Gemmell, Norman (1995) Endogenous growth, the Solow model and human capital. Economics of Planning 28(2), 169-183.

Gemmell, Norman (1996) Evaluating the impacts of human capital stocks and accumulation on economic growth: Some new evidenceë. Oxford Bulletin of Economics and Statistics 58(1), 9-28.

Goldin, Claudia and Lawrence Katz (1998) The origins of technology-skill complementarity. Quarterly Journal of Economics 113(3), 693-732.

Griliches, Zvi (1969) Capital-skill complementarity. Review of Economics and Statistics 51(4), 465468.

Laitner, John (1997) Intergenerational and interhousehold economic links. Handbook of Population and Family Economics 1, 189-238.

Maoz, Yishay and Omer Moav (2004) Social stratification, capital-skill complementarity, and the nonmonotonic evolution of the education premium. Macroeconomic Dynamics 8(3), 295-309.

National Center for Education Statistics, US Department of Education.

Patron, Rossana and Marcel Vaillant (2012) Public expenditure on education and skill formation: Is there a simple rule to maximize skills? Oxford Development Studies 40(2), 261-271.

Restuccia, Diego and Carlos Urrutia (2004) Intergenerational persistence of earnings: The role of early and college education. American Economic Review 94(5), 1354-1378.

Su, Xuejuan (2004) The allocation of public funds in a hierarchical educational system. Journal of Economic Dynamics and Control 28(12), 2485-2510.

Viaene, Jean-Marie and Itzhak Zilcha (2013) Public funding of higher education. Journal of Public Economics 108(0), 78-89.

World Bank. Available at http://databank.worldbank.org/data/views/variableselection/selectvariables .aspx?source=education-statistics- $\sim$-all-indicators\#.

Zilcha, Itzhak (2003) Intergenerational transfers, production and income distribution. Journal of Public Economics 87(3-4), 489-513.

\section{APPENDIX A: THE NECESSARY CONDITIONS THAT ENSURE NO CONVERGENCE INTO A STEADY STATE DURING THE FIRST STAGE OF DEVELOPMENT}

Let us first consider the case in which not all individuals who find it optimal to acquire higher education are able to obtain the funds to do so. In this case, $K_{t+1}=0$ and $\lambda_{t}$ is given by (19). Plugging the former into (15) and the latter into the production function with (16) yields

$$
Y_{t+1}=\Phi\left(Y_{t}\right)=A\left\{\left(B \frac{\delta}{h}\right)^{1-\alpha}\left[\theta_{t} \tau(1-\alpha)\right]^{\gamma}\right\} Y_{t}^{1-\alpha+\gamma},
$$

where $\delta \equiv \beta(1-\tau)+\left(1-\theta_{t}\right) \tau$. The derivative is given by

$$
\frac{\partial \Phi}{\partial Y_{t}}=A\left(\frac{B \delta}{h}\right)^{1-\alpha}\left[\theta_{t} \tau(1-\alpha)\right]^{\gamma}(1-\alpha+\gamma) Y_{t}^{\gamma-\alpha}>0 .
$$


Note that if $\alpha>\gamma$, all the Inada conditions are satisfied, and the dynamic equation converges into a unique steady state. If, on the other hand, this condition is not satisfied, the dynamic equation is convex. At a certain point in time, output is high enough to make investment in physical capital is profitable, and the economy moves on to the second stage of development. As long as the function $\Phi$ is convex, there is no steady state in this case. Yet if the function $\Phi$ is concave, it may also be that the economy moves on to the second stage of development. To find the parametric condition wthat ensures that the economy does not converge to a steady state in the first stage of development, we first find the steady state, and we then compute the output level at which investment in physical capital is positive and find the parametric conditions that ensure that the former level of output is higher than the steady state without investment in physical capital. The output in a steady state in this case is given by

$$
\bar{Y}=\left\{A\left[\left(B \frac{\delta}{h}\right)^{1-\alpha}\left[\theta_{t} \tau(1-\alpha)\right]^{\gamma}\right]\right\}^{1 /(\alpha-\gamma)} .
$$

Investment in physical capital becomes positive once $\lambda_{t}$, as given by (19), equals $\lambda_{t}$, as given by (18). This in turn provides the following output level:

$$
\tilde{Y}_{t}=\left[\frac{(1-\alpha)\left[\theta_{t} \tau(1-\alpha)\right]^{\gamma}}{\alpha \beta}\right]^{\frac{1}{1-\gamma}} .
$$

No convergence to a steady state in this case implies $\tilde{Y}_{t}<\bar{Y}$. This occurs if

$$
A>\left[\frac{1-\alpha}{\alpha \beta}\right]^{\frac{\alpha-\gamma}{1-\gamma}}\left\{\frac{1}{B \delta\left[\theta_{t} \tau(1-\alpha)\right]^{\gamma}}\right\} .
$$

\section{APPENDIX B: THE NECESSARY CONDITIONS FOR CONVERGENCE TO A UNIQUE STEADY STATE WHEN $\lambda_{t}<1$ AND $K_{t+1}>0$}

The dynamic equation in this case presents $Y_{t+1}$ as an increasing function of $Y_{t}$, as shown in the following equation:

$$
\begin{aligned}
& Y_{t+1}=A\left[\lambda_{t} B\left[\theta_{t} \tau(1-\alpha) Y_{t}\right]^{\gamma}\right]^{1-\alpha} \\
& \quad \cdot\left\{\alpha\left\{\beta[1-\tau(1-\alpha)] Y_{t}+\left[\theta_{t} \tau(1-\alpha) Y_{t}\right]^{\gamma}\right\}\right\}^{\alpha} .
\end{aligned}
$$

Showing analytically that the second derivative is negative is impossible. However, I now show that when output approaches zero this derivative is infinite, and when output approaches infinity the derivative approaches zero. To see this, note that the second part of the derivative approaches infinity as output approaches zero, and approaches zero as output approaches infinity. Hence, as output approaches zero, the derivative converges to infinity. To understand if the derivative is smaller than one as output converges to infinity, we should look into the first part of the derivative. If it is smaller than one, the whole expression is smaller than one. Recall equation (18), which shows that $\lambda_{t}$ is an increasing and concave function of $Y_{t}$. For the derivative to converge to zero, the highest sum of 
powers in the numerator must be smaller than the highest sum of powers in all elements in the denominator. Then the last condition is $\gamma<1$, which is a natural assumption. Hence, the dynamic equation converges to the steady state either when $\lambda_{t}<1$, or when $\lambda_{t}=1$, as shown in the proof of Lemma 2.

\section{APPENDIX C: PARAMETER VALUES}

Table C.1 details the parameters we used in our numerical simulations.

TABLE C.1. Parameter values

\begin{tabular}{lcc}
\hline Parameter & Value used in simulations & Robustness check interval \\
\hline$A$ & 5.4 & $1-10$ \\
$h$ & 2 & $0.01-5$ \\
$s$ & 0.2 & $0.03-0.3$ \\
$\alpha$ & 0.4 & $0.2-0.6$ \\
$\gamma$ & 0.12 & $0.05-0.5$ \\
$\tau$ & 0.36 & $0.2-0.55$ \\
$K_{0}$ & 0.05 & \\
$E_{0}$ & 0.01 & \\
$U_{0}$ & 0.01 & \\
\hline
\end{tabular}

